\title{
Experimental and Simulation Analysis of Hot Isostatic Pressing of Gas Atomized Stainless Steel 316L Powder Compacts
}

\author{
Dongguo Lin ${ }^{1}$, Sangyul Ha ${ }^{2, *}$, Youngho Shin ${ }^{3}$, Dong Yong Park ${ }^{4}$, Seong Jin Park ${ }^{1}$, Sung Taek Chung ${ }^{5}$, \\ Ravi Bollina ${ }^{6}$, and Seongkyu See ${ }^{7}$ \\ ${ }^{1}$ Department of Mechanical Engineering, Pohang University of Science and Technology, Pohang 37673, Republic of \\ Korea \\ ${ }^{2}$ Corporate R\&D Institute, Samsung Electro-Mechanics, Suwon 16674, Republic of Korea \\ ${ }^{3}$ Doosan Heavy Industries \& Construction Co., Ltd., Changwon 51711, Republic of Korea \\ ${ }^{4}$ Department of Solar Thermal, Korea Institute of Energy Research, Daejeon 34129, Republic of Korea \\ ${ }^{5}$ CetaTech Inc., Sacheon 52537, Republic of Korea \\ ${ }^{6}$ Mahindra Ecole Centrale, Bahadurpally Jeedimetla, Hyderabad 500043, India \\ ${ }^{7}$ POSCO, Pohang 37859, Republic of Korea
}

\begin{abstract}
In this work, both experimental and numerical studies were conducted to investigate the densification behavior of stainless steel 316L (STS 316L) powders during hot isostatic pressing (HIP), and to characterize the mechanical properties of HIPed specimens. The HIP experiments were conducted with gas atomized STS 316L powders with spherical particle shapes under controlled pressure and temperature conditions. The mechanical properties of HIPed samples were determined based on a series of tensile tests, and the results were compared to a reference STS 316L sample prepared by the conventional process, i.e., extrusion and annealing process. Corresponding microstructures before and after tensile tests were observed using scanning electron microscopy and their relationships to the mechanical properties were addressed. Furthermore, a finite element simulation based on the power-law creep model was carried out to predict the density distribution and overall shape change of the STS316L powder compact during HIP process, which agreed well with the experimental results.
\end{abstract}

(Received April 11, 2016; Accepted May 10, 2016)

Keywords: metals, hot isostatic pressing (HIP), densification, mechanical properties, computer simulation

\section{INTRODUCTION}

Hot isostatic pressing (HIP) is the one of the most reliable, efficient and practical forming processes for manufacturing near-net-shape products, and is widely used in industries including automotive, aerospace, marine and offshore, power generation, and microelectronics [1]. The components fabricated by HIP process exhibit excellent mechanical properties including high strength, resistance to stress corrosion cracking, and long fatigue life [2-4]. In the HIP process, a thin-walled container or can is used to encapsulate the powder materials under high temperature and pressure, however, the initial and final shapes of the HIPed samples differ not only in scale but also in shape as a result of spatial temperature and density gradients caused by the non-uniform deformation of the container [5]. This can induce non-uniform distribution of

*Corresponding Author: Sangyul Ha

[Tel: +82-31-300-4732, E-mail: dubuking@postech.ac.kr]

Copyright (c) The Korean Institute of Metals and Materials relative density and residual stress, and in turn produce cracks and distortion. Thus, it is important to minimize the relative density gradient when manufacturing high quality products by HIP $[3,6]$.

For several decades, a considerable amount of work on the densification behaviors of metals and ceramics powders has been conducted, both experimentally and numerically. Ashby and coworkers [7] developed HIP maps which can identify the dominant mechanisms responsible for the densification behavior of materials under specific pressures and temperatures. Many researchers have extended the HIP maps to include various materials and HIP conditions, e.g., Jeon et al. [5] on stainless steel powder, Kim et al. [8] on titanium powder, and Uematsu et al. [9] on alumina powder, among others. Although they are useful in designing a HIP schedule and determining dominant mechanisms, a numerical method should supplement those results to quantitatively consider nonlinearities coming from geometry and material. 
Table 1. Characteristics of STS 316L powders

\begin{tabular}{cccccc}
\hline \multirow{2}{*}{ Powder } & \multicolumn{2}{c}{ Particle size $(\mu \mathrm{m})$} & \multicolumn{2}{c}{ Density $\left(\mathrm{g} / \mathrm{cm}^{3}\right)$} \\
\cline { 2 - 6 } & D10 & D50 & D90 & $\begin{array}{c}\text { Apparent } \\
\text { density }\end{array}$ & $\begin{array}{c}\text { Theoretical } \\
\text { density }\end{array}$ \\
\hline STS 316L & 8.3 & 20.9 & 43.5 & $4.45(55.7 \%)$ & $7.99(100 \%)$ \\
\hline
\end{tabular}

Table 2. Chemical composition of STS 316L powder

\begin{tabular}{cccccccccc}
\hline Element & $\mathrm{Cr}$ & $\mathrm{Ni}$ & $\mathrm{Mo}$ & $\mathrm{Mn}$ & $\mathrm{Si}$ & $\mathrm{P}$ & $\mathrm{V}$ & $\mathrm{S}$ & $\mathrm{Fe}$ \\
\hline $\mathrm{wt}^{\circ} \%$ & 16.7 & 10.5 & 2.4 & 1.04 & 0.71 & 0.016 & 0.013 & 0.007 & Bal.
\end{tabular}

Nohara et al. [10] developed a numerical model which can predict the densification of a porous superalloy at high temperatures, based on a viscoplastic model of power-law creep using Shima and Oyane's yield function for porous materials at room temperature. Abouaf et al. [11] proposed a constitutive model for the densification behavior of metal powder at high temperatures by employing power-law creep and heat conduction. Kim et al. [12] investigated the experimental and theoretical densification behaviors of stainless steel powder during pressureless sintering, sinter forging, and HIP using the modified constitutive model of Shima and Oyane and the constitutive model of McMeeking and co-workers. However, they did not consider the mechanical properties and associated microstructures of the HIPed samples.

Stainless steels are widely used for HIP products due to their excellent mechanical properties. Compared to carbon steels, stainless steels usually have higher corrosion resistance, higher ductility, and higher strength and hardness $[13,14]$. Thus, a better understanding of their densification behavior and the associated mechanical properties of HIP specimens are fundamental. Jeon et al. [5] have studied the densification behavior of a stainless steel powder compact during HIP process based on a finite element simulation, using the constitutive models of Abouaf et al. and McMeeking and co-workers. They found that the simulation results produced by both models agreed very well with the experimental data for densification and deformation of stainless steel part during HIP. These works mainly addressed the effect of temperature and pressure on the density distribution in the HIPed specimen, however, they did not evaluate the mechanical properties of the HIPed specimen.
In this study, the densification behavior of $316 \mathrm{~L}$ stainless steel (STS 316L) powder during HIP was investigated experimentally and numerically, and characterization of the mechanical properties of HIPed specimens was also performed. The differences in the yield and tensile strength and fracture behaviors were analyzed in connection with the microstructural states of the specimens. Also, in order to elucidate the effect of increasing temperature on the densification behavior of STS 316L powder during HIP process, two peak temperatures were employed. Finally, a phenomenological constitutive model for predicting the densification was presented, which was validated by comparing the simulation results with the experimental results.

\section{EXPERIMENTAL PROCEDURES}

\subsection{Characterization of Stainless Steel Powders}

A gas-atomized STS 316L powder (Sandvik Korea Ltd.) was used as a model material. The principal characteristics of the powder materials are shown in Table 1 and 2. A particle size distribution analyzer was used to determine the continuous particle size distribution, in which D10, D50, and D90 are $8.3 \mu \mathrm{m}, 20.9 \mu \mathrm{m}$, and $43.5 \mu \mathrm{m}$, respectively. The theoretical density of the powder material was measured using an automatic helium pycnometer (Micromeritics AccuPyc 1330). The apparent density, which was defined as the density of the loose powders without any external force applied to them, was determined based on measurements of the volume of certain weighted loose powders, and by calculating the ratio between them. The morphology of the powder was examined by scanning electron microscopy (SEM, JEOL JSM-6390LV). As shown in Fig. 1, the powder has a spherical shape and a relatively wide range of particle size distribution.

\subsection{Hot Isostatic Pressing}

HIP experiments were carried out with a hot isostatic press (Kobelco System 30T, Kobe Steel Co., Japan) under pressure and temperature conditions controlled by a PLC programmer. The overall experimental procedure for HIP includes powder 


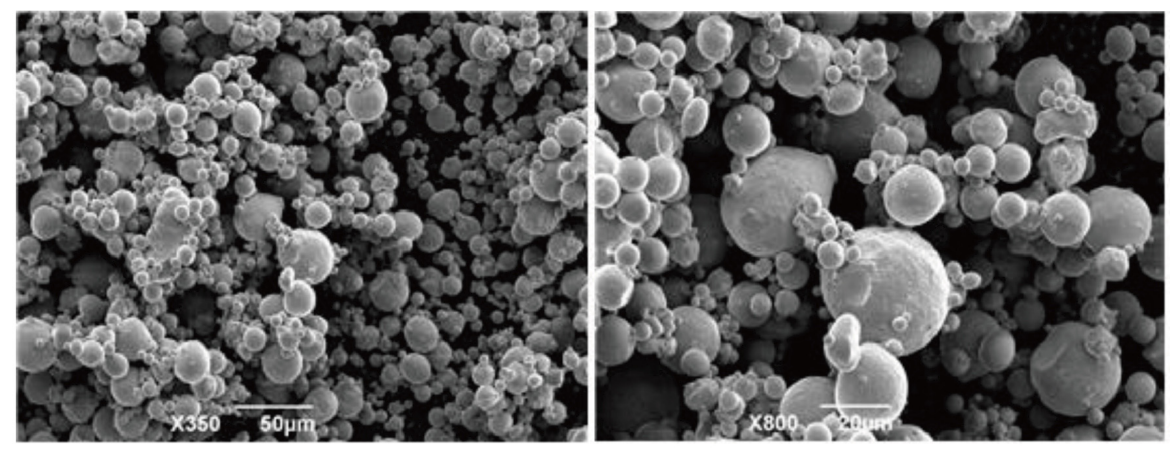

Fig. 1. SEM images for STS 316L powders: (a) $\times 350$, and (b) $\times 800$

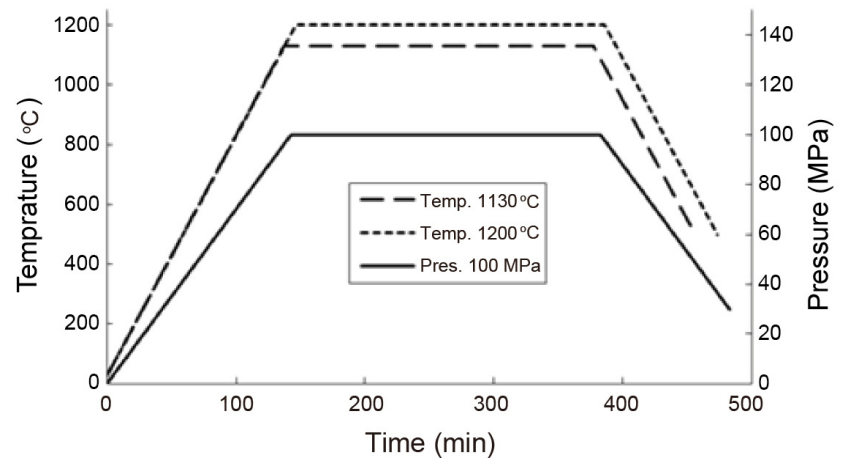

Fig. 2. Temperature and pressure schedules for HIP processes

filling, degassing, and HIPing. In the powder filling step, a cylindrical mild steel container with a $57 \mathrm{~mm}$ inner diameter, $164 \mathrm{~mm}$ in height and $1 \mathrm{~mm}$ in thickness was used to encapsulate the powder. After filling, a degassing process was followed in which the powder-filled container was constantly heated to $230{ }^{\circ} \mathrm{C}$ and held for $48 \mathrm{~h}$. Then, the container was placed within a graphite furnace located in a pressure vessel. The HIP cycle was designed with two different HIP temperatures, as shown in Fig. 2. The samples were heated up to $1130{ }^{\circ} \mathrm{C}$ and $1200{ }^{\circ} \mathrm{C}$, respectively, with a heating rate of 8 ${ }^{\circ} \mathrm{C} / \mathrm{min}$. At the same time, $100 \mathrm{MPa}$ of gas pressure was applied to the samples with a pressurization rate of 0.7 $\mathrm{MPa} / \mathrm{min}$ using argon (Ar) gas. All samples were held under the applied temperatures and pressures for $4 \mathrm{~h}$.

Then, the HIPed samples were machined into tensile test bars according to the ASTM E8 standard, to characterize their mechanical properties. Fig. 3 shows the images of final product with container after HIPing, and the prepared tensile test sample after machining. As reference samples for
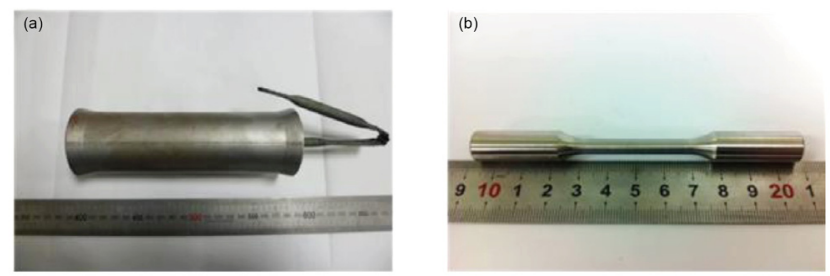

Fig. 3. Images of samples: (a) can after HIP process, (b) tensile test sample after machining

comparison, commercial STS 316L tensile test samples were also prepared by traditional extrusion and annealing processes at $1050{ }^{\circ} \mathrm{C}$.

\subsection{Characterization of Mechanical Properties}

The relative density of the HIPed sample was measured by Archimedes' method using an electronic densimeter. The relative density was calculated by the ratio of bulk density to theoretical density. The mechanical properties, including tensile strength, yield strength and elongation, of the HIPed and reference samples were measured by ASTM tensile tests under a loading speed of $1 \mathrm{~mm} / \mathrm{min}$. For each sample, the tensile tests were performed at least five times, to ensure repeatability. The microstructures of both cross-section and fracture surface of each sample were observed by SEM after polished to $1 \mu \mathrm{m}$ using a diamond suspension and etched with a chemical solution $\left(2 \% \mathrm{HF}, 9 \% \mathrm{HNO}_{3}, 9 \% \mathrm{HCl}\right.$ and $80 \%$ $\mathrm{H}_{2} \mathrm{O}$ ). Also, the dimensional changes for each sample before and after HIPing were carefully measured manually. 


\section{CONSTITUTIVE MODEL}

It is widely accepted that three mechanisms are responsible for the densification of powder materials during HIP process, i.e., plastic yielding, power-law creep, and diffusional densification. In the initial stage of the HIP process under high pressure and high temperature, powder consolidation by plastic yielding is dominant [15]. Subsequent densification occurs by power-law creep and diffusional creep. In the case of metal powders, when the pressure is over $100 \mathrm{MPa}$, power-law creep is dominant for densification with relative density over $70 \%$ as shown in several studies $[5,16,17]$. In this study, therefore, both plastic yielding [15] and power-law creep [5] were assumed to be the main densification mechanisms of stainless steel powders during HIP processes.

To develop a constitutive model for the densification behavior of powder materials, the general form of the yield function, which is a function of the stress invariants and relative density, can be written as

$$
\sigma_{e q}^{2}=f l_{1}^{2}+3 c J_{2}
$$

where $\mathrm{I}_{1}\left(=\sigma_{i i}\right)$ and $\mathbf{J}_{2}\left(=\frac{1}{2} s_{i j} s_{i j}\right)$ are the first stress invariant and second deviatoric stress invariant, respectively. The parameters $c$ and $f$ are functions of the relative density $\rho$, which can be obtained from series creep experiments. Also, $\sigma_{e q}$ denotes the yield stress of the powder materials and recovers the usual von Mises stress when $\rho=1$, i.e., the full density state.

Assuming normality flow rule, the inelastic strain rate tensor can be defined as

$$
\dot{\varepsilon}_{i j}=\frac{\partial \Psi}{\partial \sigma_{i j}}=\frac{\partial \Psi}{\partial \sigma_{e}} \cdot \frac{\partial \sigma_{e}}{\partial \sigma_{i j}}=\frac{\partial \Psi}{\partial \sigma_{e}}\left(\frac{1}{\sigma_{e}}\right)\left[f l_{1} \delta_{i j}+\frac{3}{2} c s_{i j}\right]
$$

where we have considered the yield function as the plastic potential, $\Psi$.

Employing the expended power equivalence, that the viscoplastic work of the matrix material is the same as that of a porous material, one can define the strain rate of the powder materials by the following relation

$$
\sigma_{i j} \dot{\varepsilon}_{i j}=\rho \sigma_{e q} \dot{\varepsilon}_{e q}
$$

The strain-rate sensitivity of the matrix material is of the form of the power-law creep

$$
\dot{\varepsilon_{e q}}=\dot{\varepsilon_{0}}\left(\frac{\sigma_{e q}}{\sigma_{0}}\right)^{n}=A^{\prime}{ }_{0} \sigma_{e}{ }^{n}
$$

or

$$
\dot{\varepsilon}_{e}=A_{0} \sigma_{e}^{n} \exp \left(-Q_{c} / R T\right)
$$

Here, $\dot{\varepsilon}_{e}, \sigma_{e}, \dot{\varepsilon}_{0}, \sigma_{0}$, and $n$, denote the effective strain rate, the effective stress, reference strain rate, reference stress, and power-law creep exponent, respectively. $Q_{c}, T$, and $R$ are the activation energy for power-law creep, the processing temperature and gas constant, respectively.

Combining Eqs. 2-4 yields the following creep strain rate tensor

$$
\begin{aligned}
\dot{\varepsilon}_{i j} & =\frac{\rho \dot{\varepsilon}_{0} \sigma_{e}^{n-1}}{\sigma_{0}^{n}}\left(\frac{3}{2} c \sigma^{\prime}{ }_{i j}+f \sigma_{k k} \delta_{i j}\right) \\
& =A \rho \sigma_{e}^{n-1}\left(\frac{3}{2} c{\sigma^{\prime}}_{i j}+f \sigma_{k k} \delta_{i j}\right)
\end{aligned}
$$

Here, $c$ and $f$ represent the effect of hydrostatic pressure and deviatoric stress which are associated with the volume change and shape change of porous materials, respectively. The exact functional form of $f$ is known based on the analytical solution for a hollow sphere under hydrostatic pressure, while the functional form of $f$ is not exactly known. Several works have been made to estimate the functional form of $f$ based on the calculation results of unit cell model or fitting to the experimental results. In this study, the specific functional forms for the $c$ and $f$ originally proposed by Abouaf were used to predict the densification behavior of the stainless steel powder during HIP processes. 
Table 3. Parameters used in constitutive models

\begin{tabular}{ccccccc}
\hline $\mathrm{A}_{0}$ & $\mathrm{n}$ & $\begin{array}{c}\mathrm{Q}_{\mathrm{c}} \\
(\mathrm{kJ} / \mathrm{mol})\end{array}$ & $\mathrm{A}_{1}$ & $\mathrm{n}_{1}$ & $\mathrm{~A}_{2}$ & $\mathrm{n}_{2}$ \\
\hline $1 \times 10^{-11}$ & 2.5 & 338.7 & 0.16 & 1.1 & 5.23 & 0.914 \\
\hline
\end{tabular}

Table 4. Densities of samples under different shaping conditions

\begin{tabular}{cccc}
\hline $\begin{array}{l}\text { Sample } \\
\text { number }\end{array}$ & Shaping condition & $\begin{array}{c}\text { Actual } \\
\text { density } \\
\left(\mathrm{g} / \mathrm{cm}^{3}\right)\end{array}$ & $\begin{array}{c}\text { Relative } \\
\text { density }\end{array}$ \\
\hline$\# 1$ & HIPed at $1130{ }^{\circ} \mathrm{C}$ & 7.92 & $99.1 \%$ \\
\hline$\# 2$ & HIPed at $1200{ }^{\circ} \mathrm{C}$ & 7.93 & $99.2 \%$ \\
\hline$\# \mathrm{R}$ & Extruded and annealed at $1050{ }^{\circ} \mathrm{C}$ & 7.93 & $99.2 \%$ \\
\hline
\end{tabular}

$$
f(\rho)=A_{1}\left(\frac{1-\rho}{\rho-\rho_{0}}\right)^{n_{1}}
$$

and

$$
c(\rho)=1+A_{2}\left(\frac{1-\rho}{\rho-\rho_{0}}\right)^{n_{2}}
$$

In Eq. 6 the coefficient $A$ can be calculated from Eq. 2 with the material parameters $A_{0}, n$ and $Q_{c}$. The values of the three creep parameters for STS 316L powder used in this research (privately provided by CetaTech Inc.) were listed in Table 3. Also, in Eqs. 7 and 8 the $\rho_{0}$ has a value of $\rho_{0}=0.68$, which is the value of initial packing density, and the material parameters $A_{1}, n_{1}, A_{2}$ and $n_{2}$ were obtained from the previous researches $[5,12]$ as summarized in Table III.

\section{RESULT AND DISCUSSION}
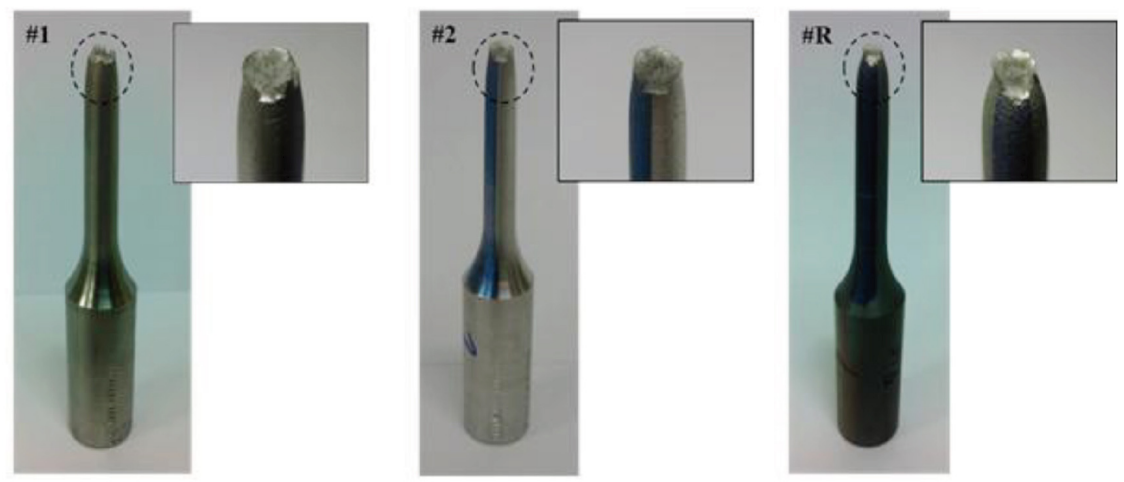

Fig. 4. Images of three different kinds of samples after tensile tests

Table 5. Mechanical properties of HIPed samples under different process conditions

\begin{tabular}{cccc}
\hline & \multicolumn{1}{c}{$\begin{array}{c}\text { Sample } \\
\text { number }\end{array}$} & Value & Ratio to "\#R" \\
\hline \multirow{3}{*}{ Tensile strength } & $\# 1$ & $707.5 \mathrm{MPa}$ & 1.21 \\
\cline { 2 - 4 } & $\# 2$ & $660.5 \mathrm{MPa}$ & 1.13 \\
\cline { 2 - 4 } & $\# \mathrm{R}$ & $586.5 \mathrm{MPa}$ & 1 \\
\hline \multirow{2}{*}{ Yield strength } & $\# 1$ & $362.5 \mathrm{MPa}$ & 1.66 \\
\cline { 2 - 4 } (YS, 0.2\% offset) & $\# 2$ & $315.5 \mathrm{MPa}$ & 1.43 \\
\cline { 2 - 4 } & $\# \mathrm{R}$ & $220 \mathrm{MPa}$ & 1 \\
\hline \multirow{3}{*}{ Elongation } & $\# 1$ & $51.0 \%$ & 0.78 \\
\cline { 2 - 4 } & $\# 2$ & $57.0 \%$ & 0.87 \\
\cline { 2 - 4 } & $\# \mathrm{R}$ & $65.5 \%$ & 1 \\
\hline
\end{tabular}

\subsection{Mechanical Properties}

For ease of explanation, the samples obtained under different shaping conditions were numbered, and their actual densities and relative densities are summarized in Table 4. All samples had relatively high densities, of over 99\%. This indicates that STS 316L parts with nearly full density can be produced by HIP process at both $1130{ }^{\circ} \mathrm{C}$ and $1200{ }^{\circ} \mathrm{C}$.

Fig. 4 shows the images of three different samples after the tensile tests. After the tensile tests, all of them had formed a "neck" which is a typical phenomenon for ductile materials. Fig. 5 shows the strain-stress curves for different samples at different strain ranges, and the results are summarized in Table 5. The results show that the HIPed samples had higher tensile strengths than the reference samples. The HIPed sample fabricated at $1130{ }^{\circ} \mathrm{C}$ had a higher tensile strength than the one at $1200{ }^{\circ} \mathrm{C}$. The yield strengths of the HIPed samples fabricated at $1130{ }^{\circ} \mathrm{C}$ and $1200{ }^{\circ} \mathrm{C}$ are respectively 362.5 $\mathrm{MPa}$ and $315.5 \mathrm{MPa}$, which were 1.6 and 1.4 times that 

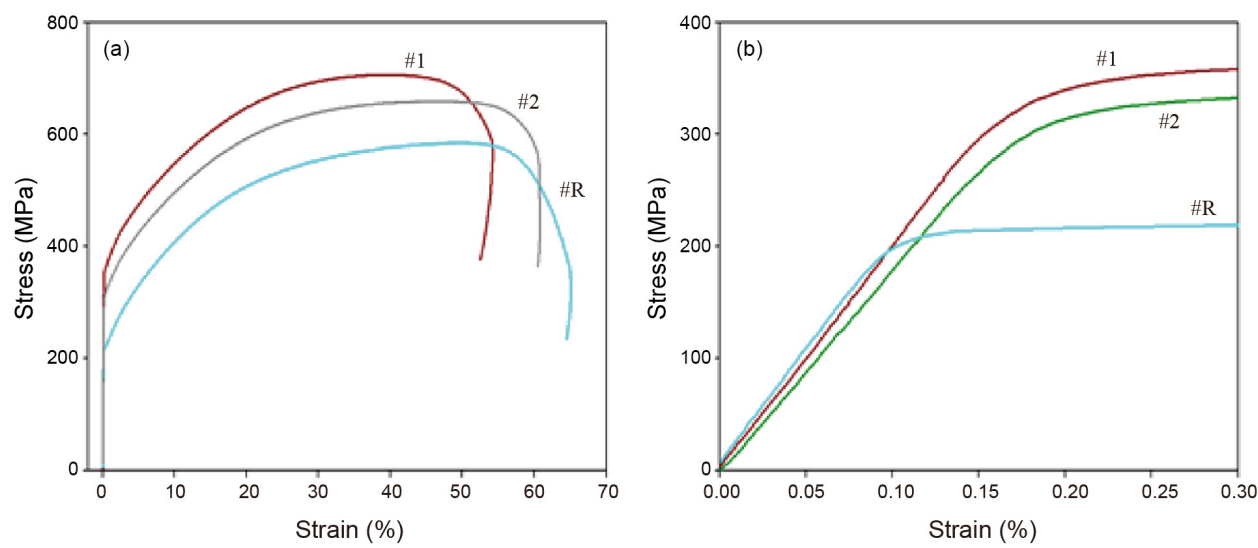

Fig. 5. Strain-stress curves for different samples: (a) at full range $(0 \sim 70 \%)$, (b) at start range $(0 \sim 0.3 \%)$
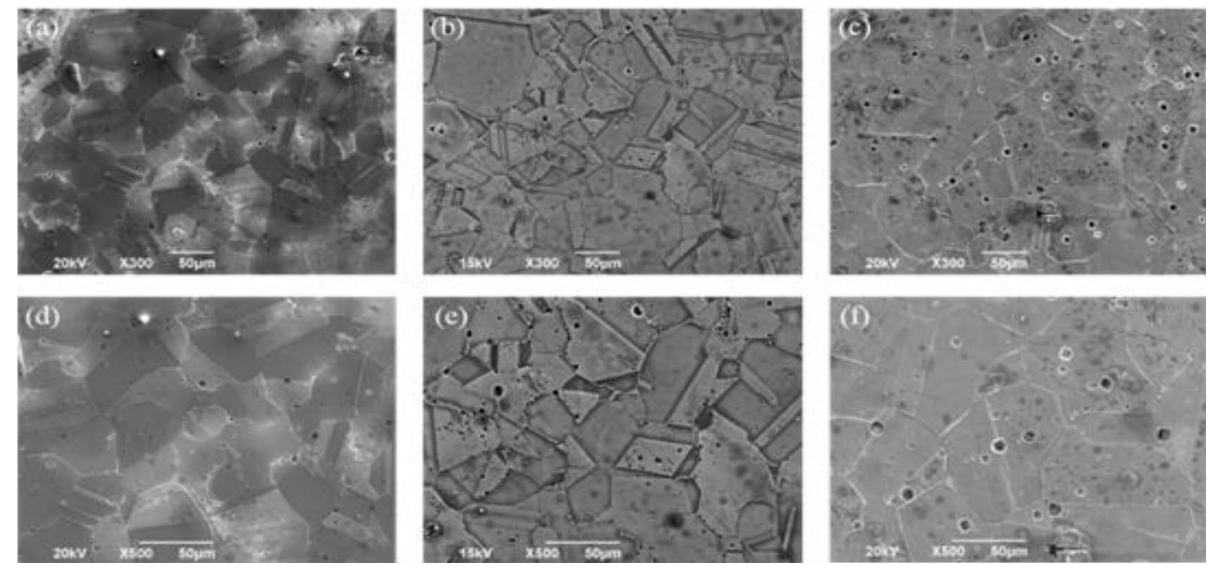

Fig. 6. Microstructures of cross-sections of different samples at different magnifications: (a) $1130{ }^{\circ} \mathrm{C}$ HIPed $(\times 300)$, (b) $1200{ }^{\circ} \mathrm{C}$ HIPed (×300), (c) reference sample $(\times 300)$, (d) $1130{ }^{\circ} \mathrm{C}$ HIPed $(\times 500)$, (e) $1200{ }^{\circ} \mathrm{C}$ HIPed $(\times 500)$, (f) reference sample $(\times 500)$

of the reference one. Similar results were observed for the tensile strength, while for elongation there was an opposite trend, where the reference sample had the largest elongation.

In summary, the HIPed samples exhibited higher tensile strength, higher yield strength but lower elongation than the reference samples. For the HIPed samples, increased peak temperature $\left(1200{ }^{\circ} \mathrm{C}\right)$ leads to a lower tensile strength, lower yield strength and larger elongation. In order to address the different mechanical properties among the samples, the microstructures before and after the tensile tests for each sample were observed and analyzed.

\subsection{Microstructures}

Fig. 6 shows the microstructures of cross-sections of three different samples after HIP process. Some small pores exist and are distributed uniformly in all three samples. However, some differences in grains can be observed. The average grain sizes for $1130{ }^{\circ} \mathrm{C}$ HIPed sample, the $1200{ }^{\circ} \mathrm{C}$ HIPed sample, and the reference samples were $32.7 \mu \mathrm{m}, 38.4 \mu \mathrm{m}$ and $61.0 \mu \mathrm{m}$ respectively for each, when calculated by average grain intercept (AGI) method. Because of the different shaping method, the reference sample had a larger grain size than the HIPed samples. It is generally understood that the HIP process allows finer and more uniform grains to be achieved compared to other manufacturing processes $[1-3,6]$ due to the short holding time at high temperatures and high pressures. Of the two HIPed samples, the $1130{ }^{\circ} \mathrm{C}$ HIPed sample had smaller and more uniform grains than the $1200{ }^{\circ} \mathrm{C}$ HIPed one. The reason was that the increased HIP temperature $\left(1200{ }^{\circ} \mathrm{C}\right)$ caused grain growth leading to a larger 

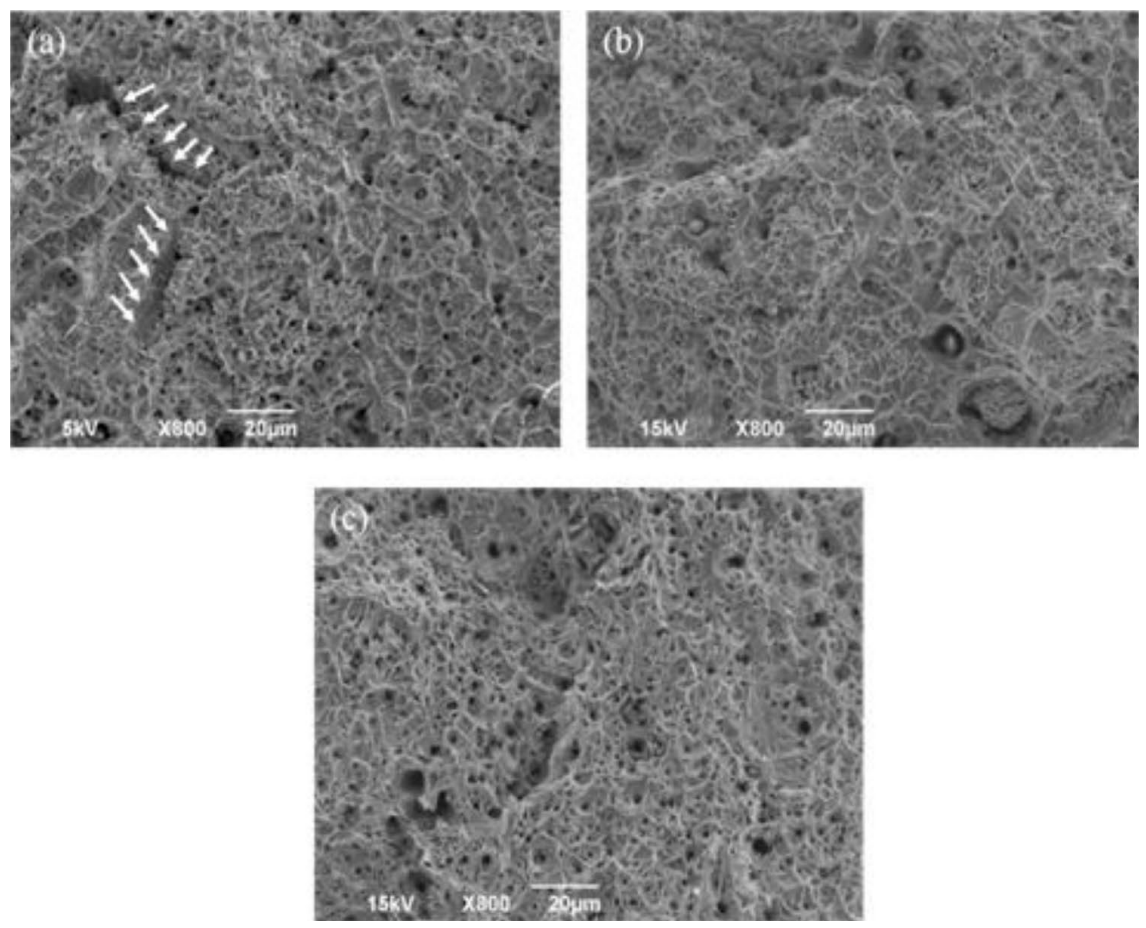

Fig. 7. Microstructures of fracture section of different samples: (a) $1130{ }^{\circ} \mathrm{C}$ HIPed, (b) $1200{ }^{\circ} \mathrm{C}$ HIPed, (c) reference sample

grain size [1,3,18-21]. A material with finer and more uniform grains should exhibit higher strength as a result of grain boundary strengthening (Hall-Petch strengthening), but lower elongation $[22,23]$. These characteristics were confirmed by the tensile tests results listed in Table 5 .

The fracture surfaces of three tensile samples were examined using SEM. Fig. 7 shows ductile dimples which developed in the vicinity of the pre-existing voids, which are indicative of typical ductile fracture. Thus, it can be concluded that the tensile failure of these samples is governed by void growth and the coalescence of initial voids. A closer examination revealed differences in void growth and coalescence mechanisms for the differently fabricated samples. For the HIPed sample at $1130{ }^{\circ} \mathrm{C}$, shown in Fig. 7 (a), it can be observed that a colony of smaller voids links the larger voids to form a void sheet mechanism, indicated by white arrows. Meanwhile, in Fig. 7 (b), two populations of void sizes were observed for the sample HIPed at $1200{ }^{\circ} \mathrm{C}$. Koplik and Needleman [24] for isotropic materials, and $\mathrm{Ha}$ and Kim [25] for anisotropic single crystals, showed that the onset of the coalescence of voids or the final failure implied by the abrupt stress drop is delayed for small initial void size.
It is believed that these large voids in the samples HIPed at $1200{ }^{\circ} \mathrm{C}$ can accelerate the loss of load carrying capacity as compared with the sample HIPed at $1130{ }^{\circ} \mathrm{C}$. In the reference sample, the fracture surface was characterized by several populations of voids of different sizes and dimples which formed around all the voids.

\subsection{Comparison between Experiment and Simulation}

The simulation was performed using PMSolver_HIP, an in-house finite element code developed by CetaTech Inc., in which the constitutive model introduced in Section 3 was implemented to predict the densification behavior of the STS 316 powder during HIP processes. A total of 5,276 continuum axisymmetric elements with hybrid formulation were used. The initial relative density was set to 0.68 , which is consistent with the measurement results, and HIPing cycles given were the same as the experimental procedures, respectively.

Fig. 8 and Fig. 9 show the simulation results for samples HIPed at $1130{ }^{\circ} \mathrm{C}$ and $1200{ }^{\circ} \mathrm{C}$ with different holding times. As holding time was increased, the relative density increased. After holding for $4 \mathrm{~h}$, the final density was $98.9 \%$. This result is almost the same as the relative density achieved in the 

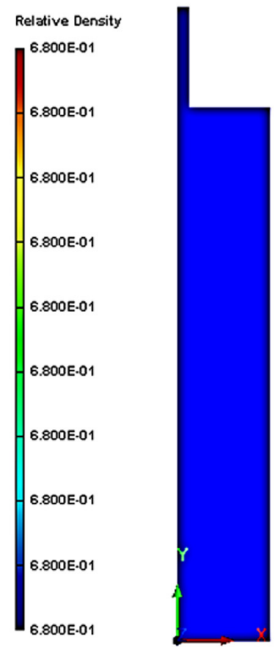

(a)
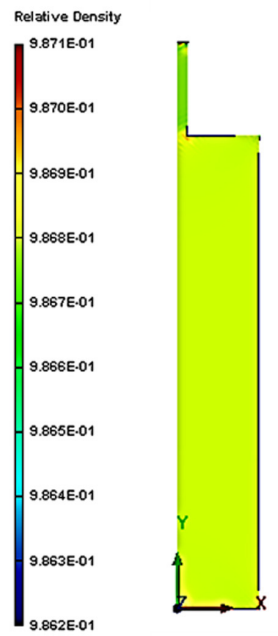

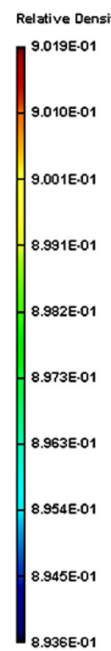

(d)

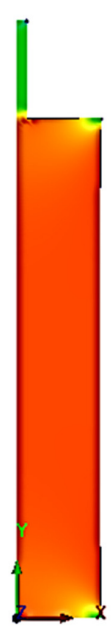

(b)

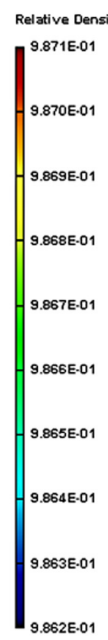

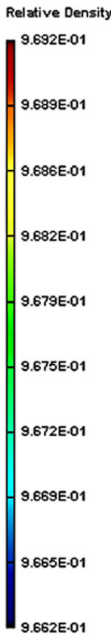

(c)

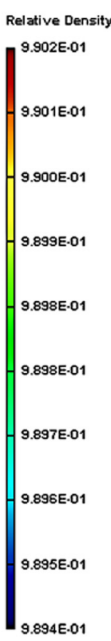

(e)
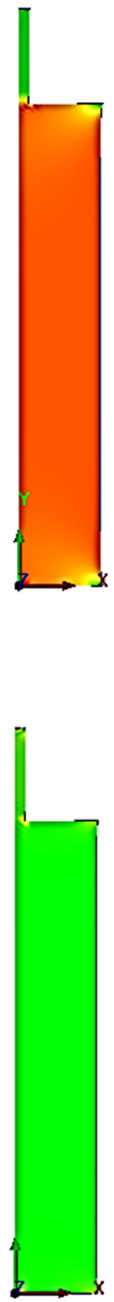

(f)

Fig. 8. Simulation results for different stages for sample HIPed at $1130{ }^{\circ} \mathrm{C}$ : (a) initial stage, (b) holding for $0 \mathrm{~h}$, (c) holding for $1 \mathrm{~h}$, (d) holding for $2 \mathrm{~h}$, (e) holding for $3 \mathrm{~h}$, (f) holding for $4 \mathrm{~h}$

experiment (99.1\%).

In addition, it can be seen that before the holding stage (Fig. 8 (a)), density gradients and anisotropic shrinkage can be observed in the simulation. There were mainly three low density regions, at the edges and corners due to the canning effect. However, during the holding stage, as holding time increased, the density gradients decreased and showed more uniform density distribution. This occurs because diffusional creep becomes the dominant mechanism during the holding stage. Fig. 8 (f) shows the final shape of the products with container after holding for $4 \mathrm{~h}$ at $1130{ }^{\circ} \mathrm{C}$ and $100 \mathrm{MPa}$. This specific shape is usually called an "elephant foot" or "hourglass effect" and is caused by the anisotropic shrinkage of the container during HIP process [26,27]. In this work, the end plates of the cylindrical container didn't shrink radially to the same value as the other cylindrical sections.

Figs. 10 (a) and (b) show the densification process for the $1130{ }^{\circ} \mathrm{C}$ and $1200{ }^{\circ} \mathrm{C}$ HIPing cycles, respectively. The triangle symbols in the figures represent the density values at different holding times from 0 to $4 \mathrm{~h}$, which correlate to the density distribution states shown in Figs. 8 and 9. At first, there was no change in density due to the low temperature. 


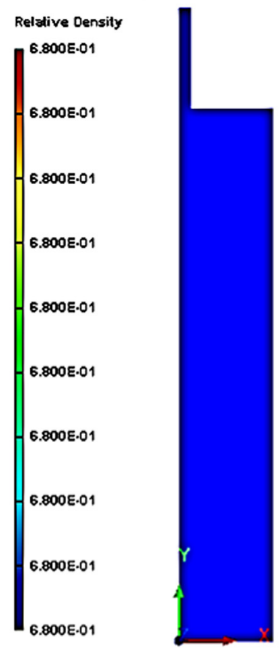

(a)

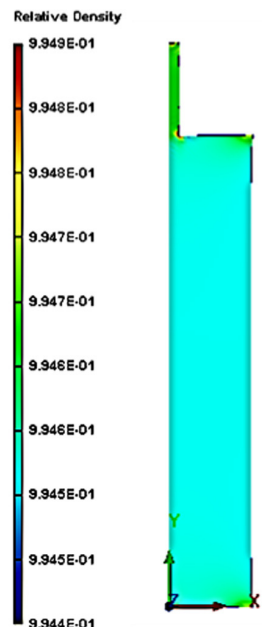

(d)
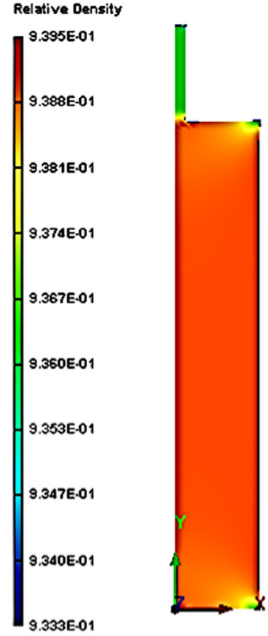

(b)

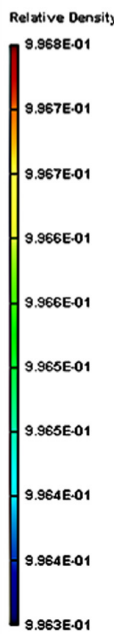

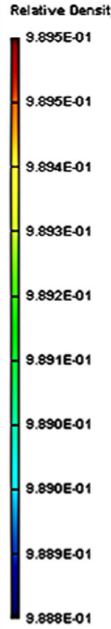

(c)

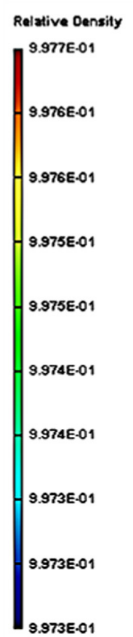

(e)
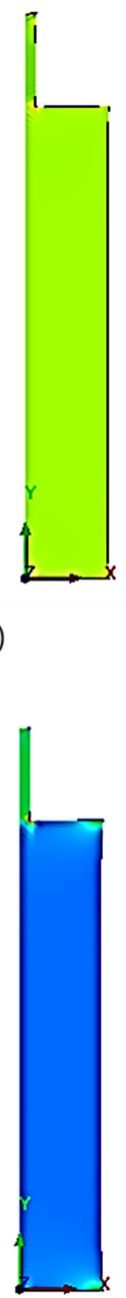

(f)

Fig. 9. Simulation results for different stages for sample HIPed at $1200{ }^{\circ} \mathrm{C}$ : (a) initial stage, (b) holding for $0 \mathrm{~h}$, (c) holding for $1 \mathrm{~h}$, (d) holding for $2 \mathrm{~h}$, (e) holding for $3 \mathrm{~h}$, (f) holding for $4 \mathrm{~h}$

Then, the density increased rapidly from $680{ }^{\circ} \mathrm{C}$ to peak temperature. Then, at holding stage, the density slowly increased with time. The final density for the $1130{ }^{\circ} \mathrm{C}$ and $1200{ }^{\circ} \mathrm{C}$ HIPing cycles were $98.9 \%$ and $99.7 \%$, respectively, which are in near agreement with the experimental results.

In order to verify the simulation results, the dimensional changes that occurred in the simulation were compared to those of the actual samples obtained from experiments. Fig. 11 shows a comparison of the dimensional changes from experiment and simulation. For both HIP conditions, the final shapes in the simulation were almost the same as those of the actual samples, which indicates that the model and parameters used in the simulation were appropriate, and the simulation was highly accurate in predicting the HIP process for STS 316L. There were slightly larger deformations in the simulation for both of the $1130{ }^{\circ} \mathrm{C}$ and $1200{ }^{\circ} \mathrm{C}$ HIP conditions. The differences between simulations and experiments in the radial direction and axial direction were 1 $\mathrm{mm}(3.7 \%$ of the diameter of the actual product $)$ and $0.4 \mathrm{~mm}$ $\left(0.3 \%\right.$ of the height of the actual product) for the $1130{ }^{\circ} \mathrm{C}$ HIP condition, and $1 \mathrm{~mm}(3.7 \%$ of the diameter of the actual product $)$ and $0.3 \mathrm{~mm}(0.3 \%$ of the height of the actual 

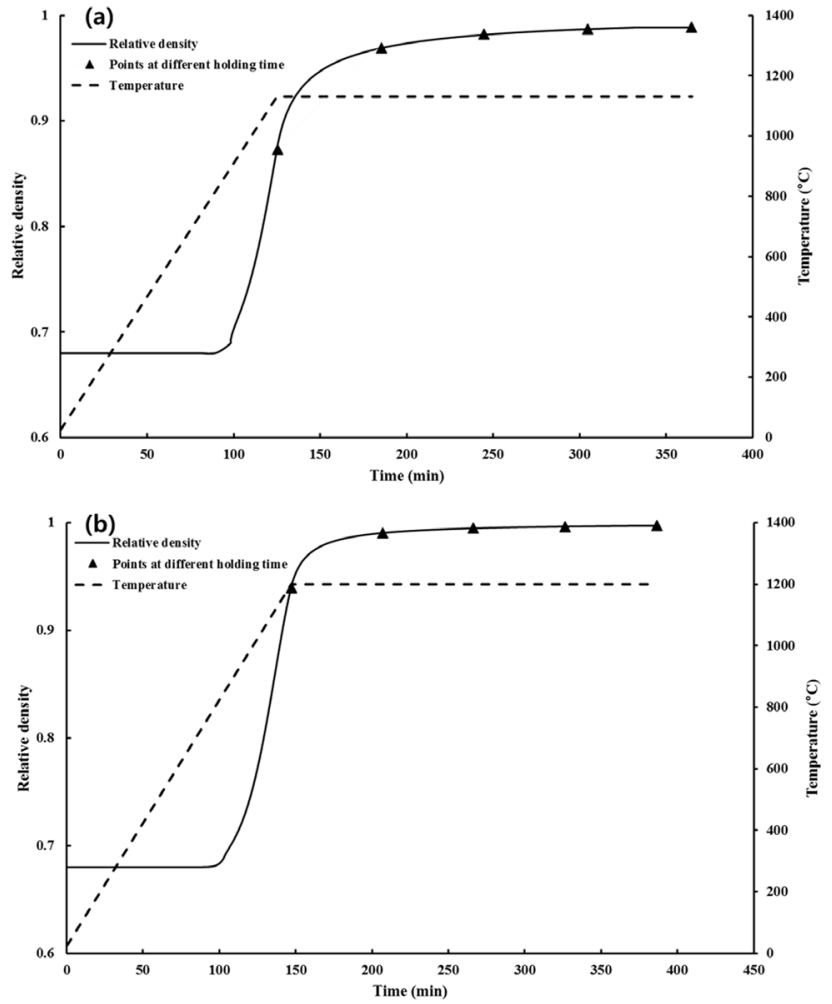

Fig. 10. Relationship between density increment, temperature and time after simulation: (a) at $1130{ }^{\circ} \mathrm{C},\left(\right.$ b) at $1200{ }^{\circ} \mathrm{C}$

product) for the $1200{ }^{\circ} \mathrm{C}$ HIP condition, respectively. The results showed that the HIP simulation for the STS $316 \mathrm{~L}$ powder was successfully developed with a very small value of error.

\section{CONCLUSION}

In this paper, both experimental and numerical studies were conducted to investigate the densification behavior of stainless steel 316L (STS 316L) powders during hot isostatic pressing (HIP) and to characterize the mechanical properties of the HIPed specimens. The HIP experiments were conducted using a STS $316 \mathrm{~L}$ powder with a spherical particle shape under controlled pressure and temperature conditions, and the mechanical properties of the HIPed samples were determined in series of tensile tests. The corresponding microstructures before and after tensile tests were observed by scanning electron microscopy (SEM) and the features' relationships to the mechanical properties were addressed.
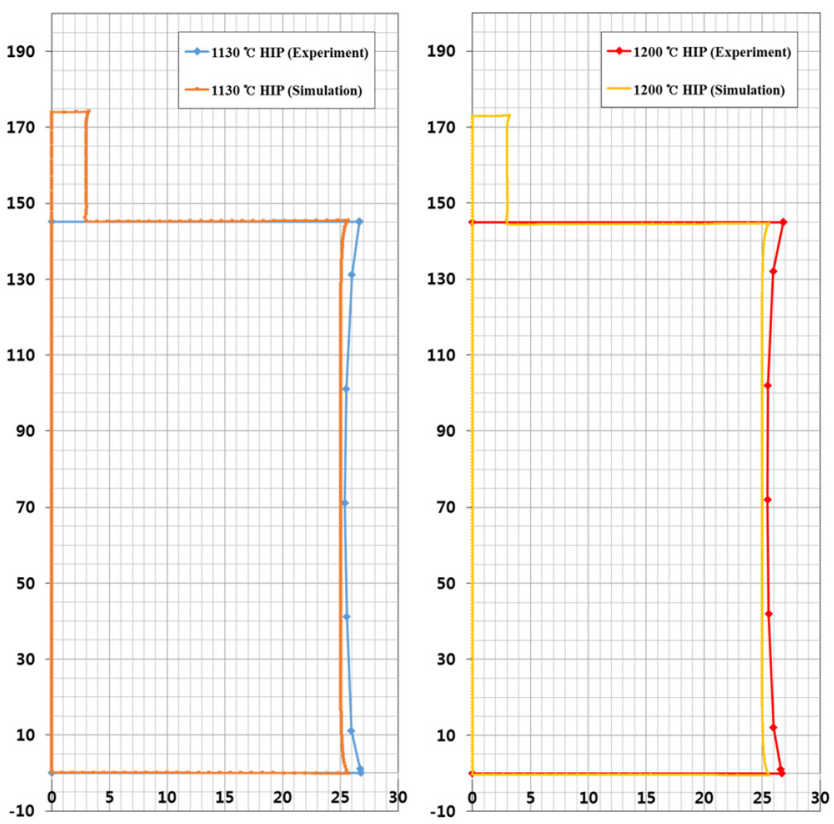

Fig. 11. Comparison of dimension changes between simulation and experiment after HIP process (unit: $\mathrm{mm}$ ): (a) $1130{ }^{\circ} \mathrm{C}$ HIPed, (b) $1200{ }^{\circ} \mathrm{C}$ HIPed

The results showed that the samples made by HIP process had smaller and more uniform grains, and possessed higher tensile strength and yield strength but lower elongation than reference samples made by extrusion and annealing. The samples that were HIPed at a higher temperature $\left(1200{ }^{\circ} \mathrm{C}\right)$ had lower tensile strength and yield strength but higher elongation in comparison to samples HIPed at a lower temperature $\left(1130{ }^{\circ} \mathrm{C}\right)$. This is attributed to the higher HIP temperature, which causes non-uniform grain growth, thereby decreasing the strength and increasing the elongation.

In addition, a FE model was developed to simulate the densification behavior of the STS 316L powder compacted during the HIP process, assuming that the dominant densification mechanism was power-law creep. The simulation results, predicting final density and product shape, were in close agreement with the actual results obtained from experiments. The difference between simulation and experiment was $3.7 \%$ in the radial direction and $0.3 \%$ in the axial direction. Thus, it can be concluded that the model adopted to predict the HIP behavior of the STS powders provides excellent correlation to the experimental results. 


\section{ACKNOWLEDGEMENTS}

This work was supported by the POSCO Research Project (2011Y117), National Research Foundation of Korea (NRF) grant funded by the Korean government (MEST) (No. 2011-0030075), and the framework of Research and Development Program of the Korea Institute of Energy Research (KIER) (B6-2415-03).

\section{REFERENCES}

1. P. E. Price, S. P. Kohler, Hot isostatic pressing of metal powders, Metals Handbook, p.419, American Society for Metals, USA (1984).

2. P. C. James, Isostatic pressing technology, Applied Science Publishers Ltd., London \& NY (1983).

3. H. V. Atkinson and S. Davies, Metall. Mater. Trans. A 31, 2981 (2000).

4. Battelle MCIC Report No. MCIC-77-34, Columbus Laboratories, Battelle, Columbus (1987).

5. Y. C. Jeon and K. T. Kim, Int. J. Mech. Sci. 41, 815 (1999).

6. M. H. Bocanegra-Bernal, J. Mater. Sci. 39, 6399 (2004).

7. M. F. Ashby, Background Reading: HIP 6.0, University of Cambridge, UK (1990).

8. K. T. Kim and H. C. Yang, Powder Metall. 44, 41 (2001).

9. K. Uematsu, K. Itakura, N. Uchida, K. Saito, A. Miyamoto, and T. Miyashita, J. Am. Ceram. Soc. 73, 74 (1990).

10. A. Nohara, T. Nakagawa, T. Soh, and T. Shinke, Int. J. Numer. Meth. Eng. 25, 213 (1988).

11. M. Abouaf, J. L. Chenot, G. Raisson, and P. Bauduin, Int. J. Numer. Meth. Eng. 25, 191 (1988).
12. K. T. Kim and Y. C. Jeon, Mater. Sci. Eng. A 245, 64 (1998).

13. U. B. Baek, B. H. Choe, J. H. Lee, J. H. Shim, E. S. Kim, and S. H. Nam, Korean J. Met. Mater. 53, 20 (2015).

14. J-Y. Lee, J-N. Kim, and C-Y. Kang, Korean J. Met. Mater. 53, 919 (2015).

15. A. S. Helle, K. E. Eastering, and M. F. Ashby, Acta Metall. Sin. 33, 2163 (1985).

16. Y. -S. Kwon, Study on high-temperature densification forming process of ceramic powder, Pohang University of Science \& Technology, South Korea (1994).

17. Y. -S. Kwon and K. T. Kim, J. Eng. Mater. Technol. 118, 471 (1996).

18. S. J. L. Kang, Sintering: Densification, grain Growth, and microstructure, Elsevier Butterworth-Heinemann, USA (2005).

19. N. L. Loh and K. Y. Sia, J. Mater. Process. Tech. 30, 45 (1992).

20. Y. -S. Kwon, S.-H. Chung, C. Binet, R. Zhang, R. S. Engel, N. J. Salamon, and R. M. German, Adv. Powder Metall. Part. Mater. 9, 131 (2002).

21. H. S. Kim, Y. Y. Kim, D. K. Park, and I. S. Ahn, J. Kor. Powd. Met. Inst. 20, 203 (2013).

22. S. X. Li and G. R. Cui, J. Appl. Phys. 101, 083525 (2007).

23. M. -W. Wu, Z. -K. Huang, C. -F. Tseng and K. -S. Hwang, Met. Mater. Int. 21, 531 (2015).

24. J. Koplik and A. Needleman, Int. J. Solids Struct. 24, 835 (1988).

25. Ha and K. T. Kim, Int. J. Mech. Sci. 52, 863 (2010).

26. E. Olevsky, S. Van Dyck, L. Froyen, and L. Delaey, Proc. HIP '96, p.63, ASM International Andover, Massachustts, USA (1996).

27. S. -P. Lee, J. -R. Lee, T. -J. Chung, Y. -K. Paek, S. -H. Yang, G. -S. Hong and K. -S. Oh, Met. Mater. Int. 21, 1038 (2015). 